\title{
Rationality of Prescriptions for Patients Admitted With Common Illnesses in a Children's Hospital
}

\author{
Farideh Shiva, ${ }^{1}$ Roxana Ghanaie,, ${ }^{1,}$ Fariba Shirvani, ${ }^{1}$ Shahnaz Armin, ${ }^{1}$ Sedigheh Rafiei Tabatabaei, \\ Seyed Alireza Fahimzad, ${ }^{1}$ Fatemeh Fallah, ${ }^{1}$ Ahmad Reza Shamshiri, ${ }^{1}$ Samira Sayyah, ${ }^{1}$ and Abdollah \\ Karimi $^{1}$ \\ ${ }^{1}$ Pediatric Infections Research Center, Mofid Children's Hospital, Shahid Beheshti University of Medical Sciences, Tehran, IR Iran \\ "Corresponding author: Roxana Ghanaie, Pediatric Infections Research Center, Mofid Children's Hospital, Shahid Beheshti University of Medical Sciences, Tehran, IR Iran. Tel: \\ +98-9123182084, E-mail: roxanaghanaie@yahoo.com
}

Received 2016 February 08; Revised 2016 April 19; Accepted 2016 April 19.

\begin{abstract}
Background: Recent advances in medicine and the pharmaceutical industry have led to a multitude of treatment options for the management of illness in both adults and children.

Objectives: To identify prescribing patterns for children hospitalized with common acute illnesses in a tertiary-care children's hospital.

Materials and Methods: Case notes of children hospitalized from October 2013 to September 2014 with urinary tract infection, respiratory distress, pneumonia, acute gastroenteritis, febrile convulsions, acute bacterial meningitis, and fever with rash or without a localized source, as well as case notes of previously healthy children scheduled for surgery, were reviewed. Relevant data regarding diagnoses, hospital course, and treatment were documented on information sheets and reviewed independently by two members of the faculty (pediatric infectious disease specialists) to evaluate the appropriateness of prescriptions given for each patient.

Results: A total of 227 case notes were reviewed, 129 (56.8\%) of which belonged to male patients. No medication was prescribed for 13 patients, whereas 697 drug prescriptions (excluding intravenous fluids) were given for 214 patients, equaling 3.25 drugs/patient; antibiotics were prescribed for 161 children (70.92\%). Overall, $87.96 \%$ of drugs were prescribed by their generic names; $20 \%$ of prescribed medications were unnecessary; the dose was incorrect in $15 \%$ of prescriptions; and the duration of treatment was inappropriate in about $27 \%$ of prescriptions. Only $29 \%$ of children with acute diarrhea received oral rehydration therapy.

Conclusions: Findings reveal a significant degree of prescription errors, emphasizing the need for stringent surveillance.
\end{abstract}

Keywords: Prescription Practice, Drugs, Medications, Antibiotics

\section{Background}

Recent advances in medicine and the pharmaceutical industry have led to a multitude of treatment options for the management of illness in both adults and children. The availability of new medications has been accompanied by an increase in overprescribing for common ailments in children, a problem that has been reported worldwide, both from developed and developing countries (1-3). Several authors have documented global irrational prescribing patterns; examples of medication misuse include almost all categories of medications, with analgesics, cough and cold medications, and antibiotics occupying the top of the list, for outpatients and inpatients alike (1). A particularly worrisome aspect of irrational prescribing is the unnecessary use of injections in the pediatric population. According to reports from the world health organization (WHO), approximately 16 billion injections are prescribed every year worldwide; more than $70 \%$ of these in- jections are unnecessary, and a sizeable proportion are unsafe and may lead to transmission of blood-borne infections like Hepatitis B, Hepatitis C, or the human immunodeficiency virus (4). Unnecessary medications increase health-care costs for families, create an avoidable burden on the health-care system of a country, and may cause adverse effects, thus augmenting the damage (5). The rate of drug exposure in children varies across different parts of the world; in most countries, the highest prescription rates have been reported for preschoolers, and the rates decline for patients older than 6 years of age (1). According to the WHO, "Rational use of medicines requires that patients receive medications appropriate to their clinical needs, in doses that meet their own individual requirements, for an adequate period of time, and at the lowest cost to them and their community"(6). Inappropriate prescribing, by contrast, may include prescribing medications unnecessarily, prescribing the wrong drug, prescribing an incorrect dosage, or failing to prescribe drugs when they are 
needed. Systematic reviews have estimated that almost $50 \%$ of in-hospital admissions and a significant percentage of medication orders may be prone to prescribing errors (7).

It is crucial that health-care professionals be trained to prescribe in accordance with evidence-based national and/or international guidelines. In addition to cutting prescription costs, prescribing according to standard guidelines has been shown to improve the effectiveness of the management of different medical problems.

\section{Objectives}

This study was carried out to identify prescribing patterns and determine the prevalence and the nature of prescribing errors for patients hospitalized with common illnesses in a university-affiliated children's hospital in Tehran.

\section{Materials and Methods}

Case notes of children hospitalized during the study period of one year, from October 2013 to September 2014, were reviewed by members of the study team.

Children admitted with respiratory distress or fever with rash and those with one of the following discharge diagnoses were included: urinary tract infection (UTI), acute gastroenteritis, pneumonia, febrile seizures, acute bacterial meningitis, fever without localizing signs (FWLS), and those undergoing surgery.

Charts of patients with underlying chronic diseases, major congenital malformations, immunodeficiency, or debility were excluded.

Trained members of the study team included one pediatric resident, one epidemiologist, and eight members of the faculty (one microbiologist, one pediatrician, and six pediatric infectious disease specialists). Recommendations from the WHO protocol DAP 93.1 were applied in designing this study; patient demographic data, diagnosis, and prescribed medications were recorded (8).

Relevant data, including chief complaints, clinical manifestations, results of investigations, admission and discharge diagnoses, duration of hospitalization, number, name, dosage and route of administration of the drugs prescribed at admission, and any change in treatment, were extracted from the files and documented on information sheets.

The information sheets were then reviewed independently by two members of the faculty (pediatric infectious disease specialists) to evaluate the appropriateness of prescriptions given for each patient. Treatment was deemed rational and appropriate if conformed to standard national and/or international guidelines as specified in textbooks, WHO recommendations, clinical journals, or in-hospital protocols. If these two members had differing opinions about any aspect of management, the files were given to a third member for a final decision.

All data were then transferred to the PASW statistics data editor, and the percentage of drugs used for different patients was calculated, along with the rationality of prescriptions, dosing errors, and treatment duration.

\section{Results}

A total of 227 case notes were reviewed; 129 charts (56.8\%) belonged to male patients. Pediatric residents made the initial diagnoses in 113 patients (49.8\%), and fellows or attending physicians did so in 114 cases (50.2\%). The discharge diagnoses were made by residents in $18 \%$ of the patients, by fellows in $11.9 \%$, and by attending physicians in $69.2 \%$.

Particulars of medications prescribed for different diagnoses are summarized in Table 1.

Overall, $87.96 \%$ of drugs were prescribed by their generic names; however, antiasthma medications, namely ipratropium bromide inhalers and albuterol nebulizers, were prescribed by trade names in $75 \%$ and $67 \%$ of cases, respectively (Tables 2 and 3). Almost 20\% of drug prescriptions were deemed unnecessary or irrational by members of the study team (pediatric infectious disease specialists); the dose was incorrect in $15 \%$ of prescriptions, and the duration of treatment was inappropriate in about 27\% (Table 2).

While 13 patients scheduled for surgery did not receive any medications (in addition to those needed for preoperative care), 697 drug prescriptions (excluding intravenous fluids) were given for 214 patients (3.25 drugs/patient). Antibiotics were not prescribed for 66 patients (29.07\%), whereas 273 antibiotic prescriptions were given for 161 children (70.92\%), equaling 1.7 antibiotics/patient (Table 1 ).

The most commonly prescribed drug was ceftriaxone, with rational prescriptions given for $72.3 \%$ of patients, followed by the antipyretic acetaminophen, given to 59 patients, with a rational prescription rate of $>96 \%$ (Table 3 ).

Of 30 patients scheduled for surgery, 16 were given 28 prescriptions for antibiotics (1.75 antibiotics/patient; Table 1).

Of 24 cases admitted with acute gastroenteritis, oral rehydration therapy was administered in only 7 cases (29.16\%), and antibiotics were administered in eight patients (33.3\%). 
Table 1. Diseases and Prescriptions Included in the Study ${ }^{\mathrm{a}}$

\begin{tabular}{|c|c|c|c|c|c|c|c|}
\hline $\begin{array}{l}\text { Disease/ } \\
\text { Presentation }\end{array}$ & No. of Patients & $\begin{array}{c}\text { Total no. of } \\
\text { Drugs } \\
\text { Prescribed, } \\
\text { Excluding IV } \\
\text { Fluids } \\
\text { (Drugs/Patient) }\end{array}$ & $\begin{array}{l}\text { No. of Patients } \\
\text { Given } \\
\text { Antibiotics }\end{array}$ & $\begin{array}{c}\text { No. of } \\
\text { Antibiotic } \\
\text { Prescriptions } \\
\text { (Antibi- } \\
\text { otic/Patient) }\end{array}$ & $\begin{array}{l}\text { Most Prescribed } \\
\text { Drug }\end{array}$ & $\begin{array}{l}\text { No. of Different } \\
\text { Drugs }\end{array}$ & $\begin{array}{l}\text { Most Prescribed } \\
\text { Antibiotic }\end{array}$ \\
\hline UTI & $47(20.7)$ & $81(1.72)$ & $47(100)$ & $78(1.66)$ & Ceftriaxone & 11 & Ceftriaxone \\
\hline Pneumonia & $31(13.7)$ & $170(5.48)$ & $26(83.87)$ & $38(1.22)$ & Ceftriaxone & 58 & Ceftriaxone \\
\hline Meningitis & $25(11)$ & $105(4.2)$ & $25(100)$ & $62(2.48)$ & Vancomycin/ceftriaxone & 25 & Vancomycin \\
\hline Gastroenteritis & $24(10.6)$ & $27(1.12)$ & $9(37.5)$ & $8(0.33)$ & Zinc sulfate & 5 & Ceftriaxone \\
\hline Fever + rash & $20(8.8)$ & $115(5.75)$ & $8(40)$ & $14(0.7)$ & Acetaminophen & & \\
\hline $\begin{array}{l}\text { Respiratory } \\
\text { distress } \\
\text { (including } \\
\text { asthma) }\end{array}$ & $15(6.6)$ & $116(7.73)$ & $12(80)$ & $16(1.06)$ & $\begin{array}{l}\text { Ipratropium } \\
\text { bromide }\end{array}$ & 35 & Ceftriaxone \\
\hline FC & $22(9.7)$ & $27(1.23)$ & $11(50)$ & $16(0.72)$ & Phenobarbital & 7 & Ceftriaxone \\
\hline FWLS & $13(5.7)$ & $25(1.92)$ & $7(53.84)$ & $11(0.84)$ & Acetaminophen & 14 & Ceftriaxone \\
\hline $\begin{array}{l}\text { Surgical } \\
\text { procedures }\end{array}$ & $30(13.2)$ & $31(1.82)$ & $16(53.3)$ & $28(0.93)$ & Cephalexine & 9 & Cephalexine \\
\hline Total & 227 & $697(3.070)$ & $161(70.92)$ & $271(1.19)$ & - & - & - \\
\hline
\end{tabular}

${ }^{\mathrm{a}}$ Values are expressed as No. (\%).

Table 2. Prescription Practices ${ }^{a}$

\begin{tabular}{|c|c|c|c|c|}
\hline Diagnoses & $\begin{array}{c}\text { Drug Prescribed by Generic } \\
\text { Name }\end{array}$ & Appropriate Drug Prescribed & Appropriate Dose & $\begin{array}{l}\text { Administered for Appropriate } \\
\text { Duration }\end{array}$ \\
\hline UTI & 95 & 73.81 & 93.65 & 71.43 \\
\hline Pneumonia & 73.65 & 84.43 & 95.21 & 82.63 \\
\hline Meningitis & 85.26 & 91.58 & 91.58 & 86.31 \\
\hline Gastroenteritis & 98.08 & 84.61 & 82.69 & 88.46 \\
\hline Fever + rash & 79.46 & 88.39 & 97.32 & 83.93 \\
\hline $\begin{array}{l}\text { Respiratory distress } \\
\text { (including asthma) }\end{array}$ & 84.46 & 82.52 & 90.29 & 84.47 \\
\hline FC & 100 & 76.74 & 100 & 58.14 \\
\hline FWLS & 94.78 & 79.92 & 92.31 & 84.61 \\
\hline Surgical procedures & 78.57 & 60.71 & 21.42 & 14.82 \\
\hline Total & 87.69 & 80.30 & 84.94 & 72.75 \\
\hline
\end{tabular}

${ }^{\mathrm{a}}$ Values are expressed as \%.

\section{Discussion}

We documented a total of 875 drug prescriptions, including prescriptions for intravenous fluids for 227 patients (3.85 drugs/patient), with almost $71 \%$ of children receiving at least one antibiotic. Studies from different parts of the world have depicted widely varying prescribing patterns for both inpatients and outpatients (2, 9-12). A study of prescriptions from 20 Gambian health centers reported the mean number of drugs as 2.2 per encounter, with over $63 \%$ of patients receiving antibiotics, and a study from Minnesota recorded that $57 \%$ of children hospitalized in an academic center were administered antimicrobials $(2,10)$. A survey on prescriptions dispensed in the outpatient clinics in four pediatric hospitals in Khartoum, Sudan, documented the mean number drugs per prescription as 2.0 ; $49.3 \%$ were prescribed by their generic names, and $81.3 \%$ 
Table 3. The 21 Most Commonly Prescribed Drugs in 227 Patients, Including the 11 Most Commonly Administered Antibiotics ${ }^{\mathrm{a}}$

\begin{tabular}{|c|c|c|c|c|c|c|}
\hline Name & Times Prescribed & Data Available & Generic Name & Rational Prescription & Correct Dose & Approved Duration \\
\hline \multicolumn{7}{|l|}{ Antibiotics } \\
\hline Ceftriaxone & 113 & 112 & $96(85.71)$ & $81(72.32)$ & $99(88.39)$ & $82(73.21)$ \\
\hline Vancomycin & 39 & 39 & $36(92.3)$ & $32(82.05)$ & $35(89.74)$ & $26(66.66)$ \\
\hline Amikacin & 29 & 29 & $29(100)$ & $10(34.4)$ & $28(96.55)$ & $15(51.72)$ \\
\hline Cefotaxime & 16 & 16 & $16(100)$ & $14(87.5)$ & $15(93.75)$ & $13(81.25)$ \\
\hline Ceftazidime & 15 & 15 & $12(80)$ & $9(60)$ & $13(86.6)$ & $9(60)$ \\
\hline Azithromycin & 12 & 11 & 11 & 7 & 10 & 10 \\
\hline Ampicillin & 5 & 5 & 4 & $5(100)$ & $5(100)$ & 4 \\
\hline Clindamycin & 5 & 5 & $5(100)$ & 4 & 4 & 4 \\
\hline Imipenem & 4 & 4 & $4(100)$ & 0 & 3 & 0 \\
\hline Gentamycin & 3 & 3 & $3(100)$ & 3 & 3 & 2 \\
\hline Meropenem & 3 & 3 & $3(100)$ & 2 & 3 & 2 \\
\hline \multicolumn{7}{|l|}{ Other Medications } \\
\hline Acetaminophen & 59 & 54 & $45(83.3)$ & $52(96.29)$ & $51(94.4)$ & $50(92.59)$ \\
\hline Ventolin nebulizer & 26 & 24 & $6(25)$ & $19 / 23$ & $23 / 24$ & $20 / 23$ \\
\hline Salbutamol MDI Inhaler & 15 & 11 & $10(90.9)$ & $10(90.9)$ & $11(100)$ & $11(100)$ \\
\hline Atrovent & 12 & 12 & $4(33.3)$ & $11(91.6)$ & $12(100)$ & $11(91.6)$ \\
\hline Spray beclomethasone & 13 & 13 & $12(92.3)$ & $9(69.23)$ & $13(100)$ & $10(76.92)$ \\
\hline Epinephrine & 12 & 10 & $10(100)$ & $5(50)$ & $8(80)$ & $4(40)$ \\
\hline ORS & 11 & 10 & $10(100)$ & $9(90)$ & $7(70)$ & $9(90)$ \\
\hline Phenobarbital & 21 & 20 & $19(95)$ & $16(80)$ & $19(95)$ & $17(85)$ \\
\hline Ranitidine & 24 & 24 & $21(87.5)$ & $21(87.5)$ & $22 / 22$ & $15 / 21$ \\
\hline $\begin{array}{l}\text { Antihistamines } \\
\text { (hydroxyzine, cetirizine, } \\
\text { loratadine) }\end{array}$ & 13 & 12 & $9(75)$ & $11(91.6)$ & $11(91.6)$ & $11(91.6)$ \\
\hline Total & 447 & 430 & $365(84.88)$ & $327(76.2)$ & $392(91.5)$ & $324(76)$ \\
\hline
\end{tabular}

${ }^{\mathrm{a}}$ Values are expressed as No. (\%).

were antibiotics (11). A study of treatment charts of children hospitalized in a tertiary-care teaching hospital in West Nepal documented the median duration of hospitalization as four days and the mean number of drugs per case as 4.5 , with antibiotics administered to $69.9 \%$ of patients (12).

Findings from hospital outpatient clinics from two different studies in Nigeria reported a drug/prescription ratio varying from 3.2 to 2.8 , with $28.1 \%$ of patients receiving antibiotics and about $49 \%$ of medications prescribed by their generic names $(13,14)$.

Ceyhan et al. conducted a point prevalence survey on antimicrobial use in hospitalized children in 12 hospitals in Turkey; they reported consumption of antibiotics in $54.6 \%$ of patients and in $75.7 \%$ of those admitted to the
ICU. Inappropriate prescriptions of at least one medication were observed in $46.7 \%$ of cases; most instances of inappropriate prescription were recorded for fluoroquinolones $(81.8 \%)(15)$.

In our study, various types of prescribing errors were identified, including irrational prescriptions (20\%), dosing errors, (15\%), and administering the medication for an inappropriate duration (27\%). Reports from the United States and the United Kingdom have estimated that prescribing errors may cause adverse effects in $1 \%-2 \%$ of patients. In these studies, prescribing errors largely comprise erratic dosing and irrational decisions; although the former is more common, the latter may lead to serious adverse effects (16-18). In a study conducted in 11 wards across five hospitals in London (four of these centers were teaching 
institutions), Ghaleb et al. identified incorrect prescribing in $13.2 \%$ of their cases and found that incomplete prescriptions and incorrect dosing were frequent prescribing errors (17). Because medication doses require adjustment according to the child's weight, the likelihood of dosing errors is high; in a systematic review of 16 studies, dosing error was shown to be the most common error type, and in some cases 10 times the required dose had been prescribed (18).

In our study, most medications were prescribed by their generic names, ( $>$ 87\%); these figures are much higher than the widely varying range of $5.8 \%-74.8 \%$ reported by other authors $(2,11,13,14,19)$. The practice of prescribing drugs by their generic names cuts the cost of therapy and has been shown to increase appropriate usage (12, 19).

In our study, the most frequently prescribed drugs were antibiotics and analgesics; ceftriaxone was the most commonly prescribed antibiotic, administered to 113 patients $(49.78 \%)$, followed by vancomycin, given to 39 children (17.2\%). Acetaminophen was the most frequently prescribed antipyretic; it was interesting to note that ibuprofen was given to only four patients, who presented with fever and rash.

Regarding the management of children admitted with acute gastroenteritis, we observed an underutilization of oral rehydration therapy in patients with mild dehydration and an overuse of antibiotics and parenteral fluid therapy.

Another point of concern was the use of antibiotics in previously healthy children scheduled for surgical procedures; out of 28 antibiotic prescriptions, only four were for treatment, and the rest were solely for prophylactic use. Although the use of prophylactic antibiotics for surgical procedures is deemed inappropriate by authorities, it has been reported from other centers as well $(15,20,21)$.

The fact that the present study was conducted by reviewing case notes and not by examining the actual patients is one of its limitations, because it is possible that some clinical findings that might have prompted the use of a certain medication were not recorded in the patient's chart, resulting in our overestimation of unnecessary drug use. We attempted to minimize this limitation by choosing files of previously healthy children not receiving medications for chronic diseases who were admitted only for an acute illness. It should be noted that other authors have used chart review with or without other measures to estimate prescription patterns in their institutions $(12,15,21)$.

Our results reveal a significant degree of error in prescriptions written for children admitted for the treatment of common illnesses in a tertiary-care children's hospital. These findings underscore the need for strict vigilance and regular surveillance of the prescribing habits of the medical staff, together with regular training sessions on appropriate prescribing in pediatric practice.

\section{References}

1. Piovani D, Clavenna A, Cartabia M, Bonati M, Interregional Italian Drug Utilisation $\mathrm{G}$. Antibiotic and anti-asthmatic drug prescriptions in Italy: geographic patterns and socio-economic determinants at the district level. Eur J Clin Pharmacol. 2014;70(3):331-7. doi: 10.1007/s00228-013-1615-4. [PubMed: 24309838].

2. Risk R, Naismith H, Burnett A, Moore SE, Cham M, Unger S. Rational prescribing in paediatrics in a resource-limited setting. Arch Dis Child. 2013;98(7):503-9. doi: 10.1136/archdischild-2012-302987. [PubMed: 23661572].

3. Zhang T, Smith MA, Camp PG, Shajari S, MacLeod SM, Carleton BC. Prescription drug dispensing profiles for one million children: a population-based analysis. Eur J Clin Pharmacol. 2013;69(3):581-8. doi: 10.1007/s00228-012-1343-1. [PubMed: 22791273].

4. WHO . WHO injection safety fact sheet 2013. Available from: www. who.int/mediacentre/factsheets/fs231/en/.

5. Nicolas A, Eickhoff C, Griese N, Schulz M. Drug-related problems in prescribed medicines in Germany at the time of dispensing. Int J Clin Pharm. 2013;35(3):476-82. doi: 10.1007/s11096-013-9769-9. [PubMed: 23605073].

6. World Health Organization . Achieving Better Health Outcomes and Efficiency Gains through Rational Use of Medicines World Health Organization. ; 2010.

7. Seden K, Kirkham JJ, Kennedy T, Lloyd M, James S, McManus A, et al. Cross-sectional study of prescribing errors in patients admitted to nine hospitals across North West England. BMJ Open. 2013;3(1) doi: 10.1136/bmjopen-2012-002036. [PubMed: 23306005].

8. Chowdhury A, Das A, Diwan V, Kafle KK, Mabadeje B. How To Investigate Drug Use in Health Facilities 2013. Available from: http://apps. who.int/medicinedocs/pdf/s2289e/s2289e.pdf.

9. Holstiege J, Schink T, Molokhia M, Mazzaglia G, Innocenti F, Oteri A, et al. Systemic antibiotic prescribing to paediatric outpatients in 5 European countries: a population-based cohort study. BMC Pediatr. 2014;14:174. doi: 10.1186/1471-2431-14-174. [PubMed: 24997585].

10. Levy ER, Swami S, Dubois SG, Wendt R, Banerjee R. Rates and appropriateness of antimicrobial prescribing at an academic children's hospital, 2007-2010. Infect Control Hosp Epidemiol. 2012;33(4):346-53. doi: 10.1086/664761. [PubMed: 22418629].

11. Ahmed AM, Awad AI. Drug use practices at pediatric hospitals of Khartoum State, Sudan. Ann Pharmacother. 2010;44(12):1986-93. doi: 10.1345/aph.1P423. [PubMed: 21119094].

12. Shankar PR, Upadhyay DK, Subish P, Dubey AK, Mishra P. Prescribing patterns among paediatric inpatients in a teaching hospital in western Nepal. Singapore Med J. 2006;47(4):261-5. [PubMed:16572234].

13. Adebayo ET, Hussain NA. Pattern of prescription drug use in Nigerian army hospitals. Ann Afr Med. 2010;9(3):152-8. doi: 10.4103/15963519.68366. [PubMed: 20710106].

14. Enwere OO, Falade CO, Salako BL. Drug prescribing pattern at the medical outpatient clinic of a tertiary hospital in southwestern Nigeria. Pharmacoepidemiol Drug Saf. 2007;16(11):1244-9. doi: 10.1002/pds.1475. [PubMed: 17868193].

15. Ceyhan M, Yildirim I, Ecevit C, Aydogan A, Ornek A, Salman N, et al. Inappropriate antimicrobial use in Turkish pediatric hospitals: a multicenter point prevalence survey. Int J Infect Dis. 2010;14(1):e55-61. doi: 10.1016/j.ijid.2009.03.013. [PubMed: 19487149].

16. Dean B, Schachter M, Vincent C, Barber N. Prescribing errors in hospital inpatients: their incidence and clinical significance. Qual Saf Health Care. 2002;11(4):340-4. [PubMed: 12468694]. 
17. Ghaleb MA, Barber N, Franklin BD, Wong IC. The incidence and nature of prescribing and medication administration errors in paediatric inpatients. Arch Dis Child. 2010;95(2):113-8. doi: 10.1136/adc.2009.158485. [PubMed: 20133327].

18. Ghaleb MA, Barber N, Franklin BD, Yeung VW, Khaki ZF, Wong IC. Systematic review of medication errors in pediatric patients. Ann Pharmacother. 2006;40(10):1766-76. doi: 10.1345/aph.1G717. [PubMed: 16985096].

19. Dimri S, Tiwari P, Basu S, Parmar VR. Drug use pattern in children at a teaching hospital. Indian Pediatr. 2009;46(2):165-7. [PubMed:
19242036].

20. Hadi U, Duerink DO, Lestari ES, Nagelkerke NJ, Keuter M, Huis In't Veld D, et al. Audit of antibiotic prescribing in two governmental teaching hospitals in Indonesia. Clin Microbiol Infect. 2008;14(7):698-707. doi: 10.1111/j.1469-0691.2008.02014.x. [PubMed: 18558943].

21. Rana DA, Malhotra SD, Patel VJ. Inappropriate surgical chemoprophylaxis and surgical site infection rate at a tertiary care teaching hospital. Braz J Infect Dis. 2013;17(1):48-53. doi: 10.1016/j.bjid.2012.09.003. [PubMed: 23287545]. 